\title{
Maternal Knowledge, Attitude, and Practices about Traditional Food Feeding with Stunting and Wasting of Toddlers in Farmer Families
}

\author{
Betty Yosephin Simanjuntak ${ }^{1 *}$, Miratul Haya ${ }^{1}$, Desri Suryani ${ }^{1}$, Ali Khomsan², Che An Ahmad ${ }^{3}$
}

\author{
${ }^{1}$ Nutrition Department, Politeknik Kesehatan Kementerian Kesehatan Bengkulu, Indonesia, ${ }^{2}$ Department of \\ Community Nutrition, Faculty of Human Ecology, Bogor Agricultural University, Indonesia, ${ }^{3}$ Faculty of Nursing \\ Mahsa University, Kuala Lumpur, Malaysia
}

\begin{abstract}
Traditional foods are foods consumed by a certain ethnic group in a specific region. The habit of consuming traditional foods is usually inherited by the family members, including toddlers, of a respective generation. The study aimed to determine relationship of maternal knowledge, attitude, and practices in traditional food feeding with stunting and wasting of toddlers in the farmer families of the Central Bengkulu District. This study employed a cross-sectional design with a sample of mothers with children aged 12-59 months. The sample included a total of 115 farmer families. Data on nutritional knowledge, attitude, practices about traditional food, sex of children, and the number of family members were collected via interviews conducted with the mothers; stunting and wasting status data were collected via height and weight measurements. Data were analyzed bivariately using the chi-square test. Multivariate logistic regression analysis was also used in this study. It was found that there was a relationship between nutritional knowledge of traditional food and nutritional status of weight-for-age ( $p$-value $=0.031$ ), and there was a correlation between nutritional practices of traditional food and wasting incidence $(p$-value $=0.012$ ). According to the height-for-age index, the nutritional status was related to the maternal knowledge of traditional food, whereas the maternal nutritional practice with traditional food had a significant relationship with the weight-for-age index.
\end{abstract}

Keywords: Knowledge, practice, stunting, traditional food, wasting

\section{Introduction}

Traditional food is formed as an evolutionary result of experiences that have been inherited for years, even centuries, and served in daily dishes consumed by families. The existence of traditional food is increasingly scarce owing to the complexity of the making of food and its limited knowledge by a certain group of people. Moreover, the main ingredients used in traditional foods are extremely likely to be determined by the location where they are found. ${ }^{1}$ However, the tendency of consuming traditional foods in families is often during wedding ceremonies of the Bengkulu people. This tradition is still maintained and followed owing to their fondness, preference, and the ease to obtain the foods. Besides, as a coastal area, Bengkulu is rich in the diversity of typical fish food. This increases the wide usage of fish as the

How to Cite: Simanjutak BY, Haya M, Suryani D, Khomsan A, Ahmad CA. Maternal knowledge, attitude, and practices about traditional food feeding with stunting and wasting of toddlers in farmer families. Kesmas: Public Health Journal. 2019; 14 (2): 58-64. (doi:10.21109/kesmas.v14i2.2712) main ingredient of unique foods, especially in the coastal community. Dewi et al., ${ }^{1}$ reported that examples of tra-ditional fish-based food in Bengkulu are Pendap, Pais, Lemea, Bagar hiu, Gulai kemba'ang, and Tempoyak (fermented durian). These traditional foods have nutri-tional values and more specific tastes because the ingre-dients are obtained from local food sources, and the taste is relatively acceptable to the people of Bengkulu.

Failure of growth and development can affect an infant's life in adulthood. Nutritional status is a child development factor affected by eating habits. Healthy eating habits are mandatory for children who need to grow and solve acute dietary problems in children. ${ }^{2}$ Furthermore, Sharif et al., ${ }^{3}$ stated that the process of transforming knowledge of the Malay traditional food among generations is from mothers to their daughters

Correspondence* : Betty Yosephin Simanjuntak, Department of Nutrition, Poltekkes Kemenkes Bengkulu, Padang Harapan, Bengkulu, Indonesia, E-mail: patricknmom@yahoo.co.id, Phone: +62-736-341212

Received : October $24^{\text {th }} 2018$

Revised : May $9^{\text {th }} 2019$

Accepted : July $15^{\text {th }} 2019$ 
with an explanation of the used ingredients, cooking methods, used equipment, and cooking skills. It is also assumed that mothers with a good nutritional knowledge prefer to prepare foods for their families. Another study found that attitude scores and maternal dietary understanding were positively associated with the toddler's diet scores. ${ }^{4}$

Most people in the Bengkulu Province still depend on the agricultural sector. Farmer families usually consume foods derived from the agricultural products. Therefore, research studies on the diversity of traditional food consumption in farmer families are still rarely carried out. The latest study by Oly-Alawuba and Iheidioha in Nigeria, ${ }^{5}$ shows that stunting in children aged 2 - 5 years at $6.4 \%$ in the farming community. This is in contrast with the study by Cruz et al., ${ }^{6}$ which states that the children living in urban areas are significantly at a lower risk of stunting as compared with the children in rural areas, who belong the farmer families. ${ }^{6}$

Balanced nutrition is essential to maintain a good health and prevent malnutrition in infants, including stunting, wasting, and obesity. The anthropometric composite index is an anthropometric index that combines the three indexes, namely weight-for-age (WAZ), heightfor-age (HAZ), and weight-for-height (WHZ), to determine the nutritional status of a toddler. A study in Bengkulu showed underweight toddlers at $11.9 \%$, stunting at $28.09 \%$, and wasting at $10.46 \%$ were mostly aged 13 - 59 months. ${ }^{7}$

Mothers are the first caregiver of toddlers in aim to mainly avoid nutritional problems in children and achieve an optimal growth. Maternal knowledge, attitudes, and practices affect the change of the children's diet. Mothers with a good knowledge will implement a good feeding practice; hence, their children will be free from malnutrition; in turn, this can help the children have a good health while following better dietary practices. Subsequently, this will help the mothers in changing their family's eating behavior and practices. ${ }^{8} \mathrm{~A}$ study by Saaka, ${ }^{9}$ concluded that there is a significant relation-ship between maternal knowledge and HAZ index, but it does not have a relationship with the WHZ index nutritional status. The aim of this study was to analyze the relationship of maternal nutritional knowledge and practices of traditional foods with the stunting and wasting of children (12 - 59 months) incidences in farming families in the Central Bengkulu District.

\section{Method}

This study applied a cross-sectional study design primarily in the Central Bengkulu District from April to July 2017, with a local ethical committee of Public Health Faculty, Diponegoro University No. 31/EC/FKM/2017. The population in this study mainly comprised all moth- ers in the agricultural areas who had children aged 12 59 months at Jambu, Renah Semanek and Pagar Jati subdistricts with a total of 137 people. The total number of mothers in the study sample was 115 . Samples were selected using a purposive sampling technique. Exclusion criteria were non-farmer family heads and the children who were not able to stand upright.

The independent variables were maternal knowledge, attitudes, and practices related to the traditional food as collected by using a questionnaire consisting of 15 questions about definition, benefit, serving habits, role of traditional food for toddler. Knowledge was categorized into three categories including low (below 60\%), medium $(60 \%-80 \%)$, and high (over $80 \%)$ of all correct answers. Nutritional attitudes were categorized into "disagree" with a score cut-off point of less than 80 and "agree" with a score of greater than 80 . Practices are categorized into seldom and often.

The dependent variable was the nutritional status of toddlers that was measured based on the body length or height-for-age (Length/Age or Height/Age). Body mass was measured by using a digital scale, and the height was measured using microtoise. To assess the child's nutritional status, the weight and height of each toddler is converted into a standardized value (Z-score) by using the 2005 WHO anthropometric standards. ${ }^{10}$ A total of 10 categories of the WAZ score included being underweight if the Z-score was between -3.0 and -2.0 standard deviations (SD), and normal if $Z$-score was between -2.0 and 2.0 SD. Categories of the HAZ scores included stunting if the Z-score was over -2.0 SD, and normal if the Z-score was below -2.0 SD. Categories of the WHZ scores included wasting if the Z-score was between -3.0 $\mathrm{SD}$ and -2.0 SD, and normal if the Z-score was between $-2.0 \mathrm{SD}$ and 2.0 SD.

Editing, coding, cleaning and entry data were employed on the collected data. Univariate data analysis included maternal knowledge, attitudes, and practices about the traditional food, nutritional status (WAZ, HAZ, and WHZ), sex of children, and the number of family. Inter-group comparison was performed with bivariate analysis by using the chi-square test. Multivariate logistic regression analysis was also carried out in this study. A p-value of less than 0.05 criterion was taken to determine the statistical significance.

\section{Results}

The data of 115 farming families, specifically mothers and their children, were analyzed in this study. Questions addressed to the mothers included their nutritional knowledge, attitude, and practices about the traditional food, sex of children, and the number of family members; whereas, the children samples were only measured for their body height and weight. Traditional foods examined 
in this study consisted of snacks, side dishes, and vegetables. Traditional snacks often consumed were tart cakes, Kembang goyang, Koja sponge, and Lemang tapai. Types of side dishes were Pais fish, Bagar chicken, Lemea fish curry, and Tempoyak ikan mungkus. Vegetables consumed by toddlers were sweet and sour bamboo shoots, sweet cane egg curry, and stir-fried pucuk lumai.

Table 1 shows that out of 115 farming families, only $33.9 \%$ of mothers, who were working as farmers and

\begin{tabular}{llrr}
$\begin{array}{l}\text { Table 1. Distribution of Maternal Knowledge, Attitude, and Practices about } \\
\text { Traditional Foods in Farmers }\end{array}$ & & \\
\hline Variable & Category & n & $\%$ \\
\hline \multirow{2}{*}{ Maternal knowledge of traditional food } & Low & 11 & 9.6 \\
& Medium & 65 & 56.6 \\
\multirow{2}{*}{ Maternal attitude to traditional food } & High & 39 & 33.9 \\
\multirow{2}{*}{ Maternal practice about traditional food } & Disagree & 35 & 30.4 \\
& Agree & 80 & 69.6 \\
WAZ Index & Seldom & 94 & 80.9 \\
& Often & 21 & 19.1 \\
\multirow{2}{*}{ HAZ Index } & Underweight & 22 & 19.1 \\
\multirow{2}{*}{ WHZ Index } & Normal & 93 & 80.9 \\
& Stunting & 34 & 29.6 \\
& Normal & 81 & 70.4 \\
& Wasting & 13 & 11.3 \\
& Normal & 102 & 88.7 \\
\hline
\end{tabular}

Notes: $\mathrm{n}=$ the number of samples, $\%=$ percentage, WAZ $=$ Weight-for-Age Zscore, HAZ = Height-for-Age Z-score, WHZ = Weight-for-Height Z-score housewives, have a high knowledge of traditional food. In terms of maternal attitude on traditional foods, most of the mothers $(69.6 \%)$ showed the 'agree' attitude, but only $19.1 \%$ of them were practicing traditional foods often in their families. According to the Z-score, the WAZ index is categorized into two groups, namely underweight and normal. There are still $19.1 \%$ of toddlers with underweight nutritional status; whereas based on the HAZ index, $29.6 \%$ of the toddlers are stunted, and $11.3 \%$ of them have wasting based on the WHZ index.

Table 2 describes the distribution of maternal knowledge on traditional food. In general, mothers know the meaning of traditional foods, that is useful, but there are still mothers $(65.2 \%)$ who do not understand the danger of using coconut milk, and $60.0 \%$ do not know that traditional foods contain fiber.

As shown in Table 3, the five variables related to the WAZ index are maternal nutritional practices on traditional food ( $p$-value $=0.012)$; whereas, the variables that have no significant association with the WAZ index are maternal knowledge and attitude about traditional food, sex of children, and the number of family members.

The results of chi-square test (Table 4) showed that

Table 2. Distribution of Maternal Knowledge Based on Correct Answers

\begin{tabular}{lrr}
\hline Question & $\mathbf{n}$ & $\%$ \\
\hline Definition of traditional food & 109 & 94.8 \\
Benefits of traditional food & 109 & 94.8 \\
The danger of using coconut milk in traditional food & 65.2 \\
Traditional food serving habits & 105 & 91.3 \\
Traditional food from fresh food & 104 & 90.4 \\
Traditional food are usually consumed only for adults & 73 & 63.5 \\
The important role of traditional food for the growth of toddlers & 98 & 85.2 \\
Nutrition in traditional food & 105 & 91.3 \\
Eating traditional foods causes diarrhea & 77 & 67.0 \\
Traditional food causes obesity & 66 & 57.4 \\
Fiber content in traditional food & 69 & 60.0 \\
Traditional food takes a long processing time & 94 & 81.7 \\
Traditional food contains a source of protein that is useful for children's intelligence & 70 & 60.9 \\
Traditional food in the form of snacks do not contain artificial dyes and preservatives & 88 & 76.5 \\
Traditional snacks can be filling & 103 & 89.6 \\
\hline
\end{tabular}

Table 3. Relationship between Maternal Knowledge, Attitudes, and Practices on Traditional Food with the Weight-for-Age Z-score Index

\begin{tabular}{|c|c|c|c|c|c|c|c|c|}
\hline \multirow{3}{*}{ Variable } & \multirow{3}{*}{ Category } & \multicolumn{4}{|c|}{ WAZ Index } & \multirow{3}{*}{ Total $(n=115)$} & \multirow{3}{*}{ p-Value } & \multirow{3}{*}{ OR $(95 \% \mathrm{CI})$} \\
\hline & & \multicolumn{2}{|c|}{ Underweight $(\mathrm{n}=22)$} & \multicolumn{2}{|c|}{ Normal (n = 93) } & & & \\
\hline & & $\mathbf{N}$ & $\%$ & $\mathbf{N}$ & $\%$ & & & \\
\hline \multirow[t]{3}{*}{ Maternal knowledge of traditional food } & Low & 1 & 9.09 & 10 & 90.91 & 11 & 0.608 & - \\
\hline & Medium & 14 & 21.54 & 51 & 78.46 & 65 & & \\
\hline & High & 7 & 17.95 & 32 & 82.05 & 39 & & \\
\hline \multirow[t]{2}{*}{ Maternal attitude to traditional food } & Disagree & 5 & 14.29 & 30 & 85.71 & 35 & 0.382 & $0.618(0.208-1.833)$ \\
\hline & Agree & 17 & 21.25 & 63 & 78.75 & 80 & & \\
\hline \multirow[t]{2}{*}{ Maternal practices about traditional food } & Seldom & 1 & 4.76 & 20 & 95.24 & 21 & 0.012 & $4.308(1.168-1.460)$ \\
\hline & Often & 22 & 23.40 & 72 & 76.60 & 94 & & \\
\hline \multirow[t]{2}{*}{ Sex of children } & Male & 13 & 20.63 & 50 & 79.37 & 63 & 0.073 & $2.143(0.925-4.966)$ \\
\hline & Female & 9 & 17.31 & 43 & 82.69 & 52 & & \\
\hline \multirow[t]{2}{*}{ The number of family member } & Big & 14 & 16.28 & 72 & 83.72 & 86 & 0.287 & $0.510(0.189-1.381)$ \\
\hline & Small & 8 & 27.59 & 21 & 72.41 & 29 & & \\
\hline
\end{tabular}

Notes: $\mathrm{n}=$ number of sample, $\mathrm{OR}=$ Odds Ratio, $\mathrm{CI}=$ Confidence Interval, WAZ = Weight-for-Age Z-score 
Table 4. Relationship of Maternal Knowledge, Attitude, and Practices about Traditional Foods with the Height-for-Age Z-score Index

\begin{tabular}{|c|c|c|c|c|c|c|c|c|}
\hline \multirow{3}{*}{ Variable } & \multirow{3}{*}{ Category } & \multicolumn{4}{|c|}{ HAZ Index } & \multirow{3}{*}{ Total $(n=115)$} & \multirow{3}{*}{ p-Value } & \multirow{3}{*}{ OR $(95 \% \mathrm{CI})$} \\
\hline & & \multicolumn{2}{|c|}{ Stunting $(n=34)$} & \multicolumn{2}{|c|}{ Normal $(n=81)$} & & & \\
\hline & & $\mathbf{N}$ & $\%$ & $\mathbf{N}$ & $\%$ & & & \\
\hline \multirow[t]{3}{*}{ Maternal knowledge of traditional foods } & Low & 7 & 63.64 & 4 & 36.36 & 11 & 0.031 & - \\
\hline & Medium & 16 & 24.62 & 49 & 75.38 & 65 & & \\
\hline & High & 11 & 28.21 & 28 & 71.79 & 39 & & \\
\hline \multirow{2}{*}{ Maternal attitude to traditional foods } & Disagree & 12 & 34.29 & 23 & 65.71 & 35 & 0.436 & $1.375(0.568-3.229)$ \\
\hline & Agree & 22 & 27.50 & 58 & 72.50 & 80 & & \\
\hline \multirow[t]{2}{*}{ Maternal practices about traditional food } & Seldom & 5 & 23.81 & 16 & 76.19 & 21 & 0.523 & $0.700(0.32-2.095)$ \\
\hline & Often & 29 & 30.85 & 65 & 69.15 & 94 & & \\
\hline \multirow[t]{2}{*}{ Sex of children } & Male & 23 & 36.51 & 40 & 63.49 & 63 & 0.112 & $2.143(0.923-4.966)$ \\
\hline & Female & 11 & 21.15 & 41 & 78.85 & 52 & & \\
\hline \multirow{2}{*}{ The number of family member } & Big & 19 & 23.46 & 62 & 76.54 & 81 & 0.663 & $0.735(0.299-11.807)$ \\
\hline & Small & 10 & 29.41 & 24 & 70.59 & 34 & & \\
\hline
\end{tabular}

Notes: $\mathrm{n}$ = number of sample, $\mathrm{OR}$ = Odds Ratio, $\mathrm{CI}$ = Confidence Interval, HAZ = Height-for-Age Z-score

Table 5. Relationship of Maternal Knowledge, Attitude, and Practices on Traditional Foods with the Weight-for-Height Z-score Index

\begin{tabular}{|c|c|c|c|c|c|c|c|c|}
\hline \multirow{3}{*}{ Variable } & \multirow{3}{*}{ Category } & \multicolumn{4}{|c|}{ WHZ Index } & \multirow{3}{*}{ Total $(n=115)$} & \multirow{3}{*}{ p-Value } & \multirow{3}{*}{ OR $(95 \% \mathrm{CI})$} \\
\hline & & \multicolumn{2}{|c|}{ Wasting ( $\mathrm{n}=13)$} & \multicolumn{2}{|c|}{ Normal $(n=102)$} & & & \\
\hline & & $\mathbf{N}$ & $\%$ & $\mathbf{N}$ & $\%$ & & & \\
\hline \multirow[t]{3}{*}{ Maternal knowledge of traditional food } & Low & 1 & 9.09 & 10 & 90.91 & 11 & 0.613 & - \\
\hline & Medium & 9 & 13.85 & 56 & 86.15 & 65 & & \\
\hline & High & 3 & 7.69 & 36 & 92.31 & 39 & & \\
\hline \multirow[t]{2}{*}{ Maternal attitude to traditional foods } & Disagree & 2 & 5.71 & 33 & 94.29 & 35 & 0.201 & $0.380(0.080-1.814)$ \\
\hline & Agree & 11 & 13.75 & 69 & 86.25 & 80 & & \\
\hline \multirow[t]{2}{*}{ Maternal practices about traditional food } & Seldom & 1 & 4.76 & 20 & 95.24 & 21 & 0.07 & $0.7(0.234-2.095)$ \\
\hline & Often & 13 & 13.83 & 81 & 86.17 & 94 & & \\
\hline \multirow[t]{2}{*}{ Sex of children } & Male & 7 & 11.11 & 56 & 88.89 & 63 & 0.943 & $0.958(0.301-3.05)$ \\
\hline & Female & 6 & 11.54 & 46 & 88.46 & 52 & & \\
\hline \multirow[t]{2}{*}{ The number of family member } & Big & 14 & 16.28 & 72 & 83.72 & 86 & 0.407 & $0.492(0.147-1.647)$ \\
\hline & Small & 8 & 27.59 & 21 & 72.41 & 29 & & \\
\hline
\end{tabular}

Notes: WHZ = Weight-for-Height Z-score

Table 6. Final Variables of Multivariate Analysis

\begin{tabular}{llllll}
\hline \multirow{2}{*}{ Anthropometric Index } & Variable & \multirow{2}{*}{ p-Value } & OR & \multicolumn{2}{c}{ 95\% CI } \\
\cline { 5 - 6 } & & & & Lower & Upper \\
\hline WAZ & Maternal nutritional practice & 0.001 & 2.757 & 7.002 & 1.085 \\
HAZ & Sex & 0.040 & 2.143 & 4.966 & 0.925 \\
WHZ & Maternal nutritional practice & 0.045 & 3.071 & 9.593 & 1.018 \\
\hline
\end{tabular}

Note: WAZ = Weight-for-Age Z-score, HAZ = Height-for-Age Z-score, WHZ = Weight-for-height Z-score

maternal nutritional knowledge $(p$-value $=0.031)$ was related to the HAZ index. Many of the mothers with a higher nutritional knowledge level were having children with a normal body weight. Due to the low maternal knowledge of traditional food, stunting was observed in $63.64 \%$ of the toddlers. There was no relationship between maternal attitude to traditional foods and the toddlers' HAZ index ( $\mathrm{p}$-value $=0.436)$. There were $34.29 \%$ mothers with 'disagree' attitude on traditional foods toward the HAZ index. There was no relationship between maternal practices about traditional foods and the toddlers' HAZ index ( $\mathrm{p}$-value $=0.523$ ). There were rarely stunted toddlers $(23.81 \%)$ among the 21 mothers, who showed practices on traditional foods. It was found that stunting was higher in boys $(36.51 \%)$ than girls $(21.15 \%)$. Based on the HAZ index, $23.6 \%$ of stunted children came from the families with the 'big' number of family members which did not show much difference from families with the 'small' family members (29.41\%).

As shown in Table 5, all the variables (maternal nutritional knowledge, attitude, practices, sex of children, and the number of family members) are not related to the WHZ index. Most of mothers with low knowledge had normal WHZ index at $90.91 \%$. Mothers with 'disagree' attitude $(94.29 \%)$ on the traditional food had children with the normal (WHZ) index. In this study, 
mothers with "seldom" nutritional practices had 95.24\% were normal.

Table 6 shows that the p-value of the WAZ index was 0.001 ( $p$-value $<0.05$ with $\mathrm{OR}=2.757$ ) and $\mathrm{WHZ}$ was 0.045 (p-value $<0.05$ with $\mathrm{OR}=3.071$ ). It means that mothers who seldom practiced traditional food feeding to their children had 2.757 times higher risk of having underweight (WAZ) index than mothers who often did. In the WHZ index, the mothers who seldom practice traditional food feeding to their children had 3.071 times higher risk of having wasting (WHZ) index as compared with the mothers who often did.

\section{Discussion}

This study showed that the HAZ index was influenced by nutritional knowledge ( $\mathrm{p}$-value $=0.031$ ), and maternal nutritional practices were related to the WAZ index ( $\mathrm{p}$ value $=0.012$ ). Also, this study found no relationship of maternal knowledge, attitude, and practices with the WAZ index. This is likely due to other factors. Several factors influencing the nutritional status included sex, the number of family members, income, father's education, family income, education, and maternal employment. ${ }^{6}$ Galgamuwa et al., ${ }^{11}$ stated that being underweight is more common in the low-income households than in the high-income households. It is similar to a study in India showing that children from low-income group have a high level of unaffordability to buy foods. It shows that poverty is not the only factor responsible for malnutrition but inadequate food intake, poor hygienic habits, and environment along with low education level also can contribute to child malnutrition among the low-income groups. ${ }^{11}$

This study showed that the WHZ-based nutritional status of farmer families was not influenced by nutritional knowledge and attitude, but influenced by nutritional practices. There was a relationship between maternal understanding of dietary and WAZ (p-value $=0.031$ ). Saaka, ${ }^{9}$ stated that an increase in maternal child care knowledge may contribute significantly to the child's nutritional status in Ghana. In another study, the score of maternal nutritional attitude and knowledge was positively related to the child's diet score. ${ }^{12}$ Maternal knowledge was not only obtained from the level of education, but also received from mass media such as television. Stunting, caused by experiences of chronic nutritional deprivation, affects approximately $25 \%$ of child under-five. There is a relationship between stunting and child development in the low- and middle-income countries. ${ }^{13}$ It is estimated that the level of expertise of maternal nutrition can be useful for feeding toddlers, so that the nutritional status of children is normal. Previous studies have demonstrated a significant influence between maternal knowledge and children's nutritional status. ${ }^{14}$ In line with the study by Alawuba, ${ }^{5}$ there was a relationship of knowledge of nutritional education with the WHZ (p-value $=0.018)$, HAZ (p-value $=0.012)$, $\mathrm{WAZ}$ indexes ( $\mathrm{p}$-value $=0.026$ ).

This study showed that there was a relationship of maternal nutritional practices with the WAZ index ( $\mathrm{p}$ value $=0.012$ ). It can be seen that most mothers with a high level of nutritional knowledge could practice how to supply their food, so that their nutritional needs are fulfilled. In line with the study by Yabanci et al., 4 finding that many mothers have higher levels of nutritional practices and their children have normal weights. The study by Saaka, ${ }^{9}$ showed that maternal knowledge is correlated with HAZ, but not with WHZ index. The nutritional knowledge of traditional foods will affect mothers' ability to provide both in terms of quantity and quality to affect the food consumed by children. ${ }^{9}$ The variety of food ingredients in the family will increase the intakes of energy and other nutrients. The study by Adnan and Muniandy, ${ }^{15}$ found that the maternal know -ledge level influences the practice of feeding children and, ultimately, determines the nutritional status of children. Maternal nutritional knowledge has an im -portant role in improving the nutritional status of their children. Mothers who provide the proper nutritious food can help the children meet the needs for a better growth and nutritional status. ${ }^{16}$

The most common problem of malnutrition in toddlers is stunting. Stunting is a major public health problem in developing countries such as Indonesia as compared with underweight and wasting. The HAZbased nutritional status showed stunting to be prevalent in $6.1 \%$ of the toddlers. ${ }^{2}$ Stunting is resulted from a complex interaction of household, environmental, socioeconomic, and cultural influences that are described in the WHO Conceptual Framework on Childhood Stunting. ${ }^{17}$ This study is almost the same with the study by Alawuba in Nigeria, ${ }^{5}$ which found that stunting in children aged $2-5$ years is $6.4 \%$. However, a study on fisherman families in the Philippines found $30.3 \%$ stunting incidence in children aged 0-60 months, 18 which is in contrast to the study by Cruz et al., ${ }^{6}$ stating that children living in urban area have a significantly lower risk of stunting than children in rural areas, with a p-value $<0.001$. A study by Sarma et al. ${ }^{19}$ showed that the prevalence of stunting was found at around $41 \%$ among children under 60 months of age, and higher in rural area than in urban area (43\% versus $36 \%$ ).

Traditional food is a cultural phenomenon as they are consumed by a certain ethnic group in a specific region. Traditional foods have the potential to be a source of nutrients that is sustainable, economically, culturally acceptable and diverse, but not yet continuously used to prevent malnutrition through the diversification of tradi- 
tional food-based foods. ${ }^{3}$ In fact, the traditional source of food can be used for elevating the strategy of improving the nutrition for family with a traditional food base. Micronutrients in forms of iron, vitamin A, and vitamin $\mathrm{C}$ are mostly available in traditional foods. ${ }^{20}$ Besides, an optimization of the use of local food means that it is easily obtained and the price is relatively affordable. 4,8

Lifestyle and dietary changes lead to the increased occurrence of obesity and chronic diseases. The rapid nutrition transition in this region may be due, instead, to the increasing food availability and food purchasing po wer, rather than to a shift in food preferences toward modern Western foods. ${ }^{21}$ As a result, the micronutrient intake becomes low. Another consequence is the increase in energy, carbohydrate, and fat consumption.

Results of this study highlighted that traditional foods in Central Bengkulu included vegetable groups with traditional food ingredients mostly obtained from rice fields such as unji, lumai, kambas, lemea, umbut, round purple eggplant, ferns, white mushrooms, taro leaves, and young papaya. ${ }^{1}$ The vegetable is processed by sauteing or making chili sauce. Vegetable food ingredients which are usually processed into the sauce are unji, young papaya, lumai fruit, and lemea. By judging from these types of traditional foods, mothers usually only provided vegetable soup to their toddlers, or serve it in a small size. Traditional foods in the study location rarely used fish because the site of this study is located in an agricultural area, so that the source of the animal protein generally comes from the livestock they produce, including eggs or fish they buy in the market.

Based on the analysis results, the WHZ-based nutritional status in wasting category was at $11.3 \%$. This figure shows that the prevalence of nutritional status of very thin toddlers is higher as compared with the study by Olack et al.,22 in Kenya at $0.6 \%$. Capanzana et al., 18 showed the prevalence of wasting in children aged 0-60 months in the Philippines at $7.9 \%$ and the prevalence of overweight at $5.0 \%$. Also, a study by Derso et al., ${ }^{23}$ stated that prevalence of stunting and wasting in children aged 6-24 months in Ethiopia are 58.1\% and $17.0 \%$ respectively. Wasting is found correlated with the sex of the child, but not correlated with the households headed by fishermen and farmers. ${ }^{23}$ However, multivariate test in this study indicated that stunting was correlated with sex (Table 6).

A previous study revealed that traditional foods contributed by $30 \%-40 \%$ of the average daily energy of toddlers. Traditional foods contain a lot of sources of protein, iron, and vitamin A. Traditional foods are useful for maintaining adequate body intake. ${ }^{5}$ However, the fact shows that there is a change in feeding in family. The decline in the contribution of traditional food gradually over this century due to the knowledge of traditional foods is low, so that the available local nutrient sources are not used optimally. The loss of traditional food consumption will lead to a decrease in the diversity of diet in each tribe, and a changing lifestyle causes people to choose to buy fast food. ${ }^{5}$

\section{Conclusion}

There is a relationship of maternal nutritional practices with the nutritional status of toddlers (12-59 months) based on the WAZ and WHZ indexes in farmer families in the Central Bengkulu District. While, the sex of children has a substantial relationship with the HAZ index, it is necessary to improve the maternal understanding of traditional food, so that the mothers of the toddlers can practice the feeding in order to improve the child's nutritional status. The traditional source of food can be used for elevating the strategy of improving the nutrition for family with a traditional food base. Micronutrients including iron, vitamin A, and vitamin C are mostly available in traditional foods. On the other hand, an optimization of local food means that it is easily obtained and the price is relatively affordable.

\section{Acknowledgment}

The authors would like to thank the Neys-van Hoogstraten Foundation for funding this study. Appreciation is addressed to the Director of Health Polytechnic of Bengkulu, the Dean of Faculty of Human Ecology, Bogor Agricultural University.

\section{References}

1. Dewi KH, Silsia D, Susanti L. Bengkulu industry mapping of "Lemea" rejang traditional food in Bengkulu Province. Agrisep. 2014; 14(1): 619.

2. Al-Shookri A, Al-Shukaily L, Hassan F, Al-Sheraji S, Al-Tobi S. Effect of mothers nutritional knowledge and attitudes on Omani children's dietary intake. Oman Medical Journal. 2011; 26(4): 253-7.

3. Sharif MSM, Nor NM, Zahari MSM. The effects of transmission of malay daily food knowledge on the generation practices. Procedia - Soc Behav Sci [Internet]. 2013; 85: 227-35.

4. Yabancı N, Kısaç İ, Karakuş SŞ. The effects of mother's nutritional knowledge on attitudes and behaviors of children about nutrition. Procedia-Soc Behav Sci. 2014; 116: 4477-81.

5. Oly-Alawuba, Ihedioha SA. Nutritional knowledge of mothers/caregivers and anthropometric indices of children (2-5 years) in Obowo local government area, Imo State, Nigeria. International Journal of Innov ative Studies in Science and Engineering Technology. 2018; 4(1): 1923.

6. García Cruz L, González Azpeitia G, Reyes Súarez D, Santana Rodríguez A, Loro Ferrer J, Serra-Majem L. Factors associated with stunting among children aged 0 to 59 months from the central region of Mozambique. Nutrients Journal. 2017; 9(5): 491-507.

7. Simanjuntak BY, Haya M, Suryani D, Ahmad CA. Early inititation of 
breastfeeding and vitamin a supplementation with nutritional status of children aged 6-59 months. Kesmas: National Public Health Journal 2018; 12(3): 107-13.

8. Edith M, Priya L. Knowledge, attitude, and practice (KAP) survey on dietary practices in prevention of malnutrition among mothers of under-five children. Manipal Journal of Nursing and Health Sciences. 2016; 2(2): 19-24.

9. Saaka M. Relationship between mothers' nutritional knowledge in childcare practices and the growth of children living in impoverished rural communities. Journal of Health, Population and Nutrition. 2014; 32(2): $237-48$.

10. Direktorat Jenderal Bina Gizi dan Kesehatan Ibu dan Anak. Keputusan Menteri Kesehatan Republik Indonesia No. 1995/Menkes/SK/XII/2010 tentang standar antropometri penilaian status gizi anak. Kemenkes RI; 2011.

11. Galgamuwa LS, Iddawela D, Dharmaratne SD, Galgamuwa GLS. Nutritional status and correlated socio-economic facto rs among preschool and school children in plantation communities, Sri Lanka. BMC Public Health. 2017;17(1):1-11.

12. Vereecken C, Rovner A, Maes L. Associations of parenting styles, parental feeding practices and child characteristics with young children's fruit and vegetable consumption. Appetite. 2010; 55(3): 589-96.

13. Perkins JM, Kim R, Krishna A, McGovern M, Aguayo VM, Subramanian $\mathrm{S} \mathrm{V}$. Understanding the association between stunting and child development in low and middle income countries: Next steps for research and intervention. Social Science and Medicine. 2017; 193: 101-9.

14. Pawenrusi EP. Factors Related to the nutritional status of children in area served by the Pattingalloang Health Center, Makassar. Pakistan Journal of Nutrition. 2016; 15(4): 333-6.

15. Adnan N, Muniandy ND. The relationship between mothers' educational level and feeding practices among children in selected kindergartens in Selangor, Malaysia: A cross-sectional study. Asian Journal of Clinical Nutrition. 2012; 4: 39-52.

16. Farhana JA, Akther F, Talukder MU, Islam A, Islam T, Bhuyan AH. Role of mothers' nutritional knowledge, nutritional factors on the school performance. International Journal of Public Health Science. 2015; 4(1): 44-9.

17. Steward CP, Iannotti L. Dewey KG, Michaelsen KF, Onyango AW. Contextualizing complementary feeding in broader framework for stunting prevention. Maternal\& Child Nutrition. 2013; 9: 27-45.

18. Capanzana MV, Aguila DV, Gironella GMP, Montecillo KV. Nutritional status of children ages $0-5$ and $5-10$ years old in households headed by fisherfolks in the Philippines. Archives of Public Health. 2018; 76(24): $1-8$.

19. Sarma H, Khan JR, Asaduzzaman M, Uddin F, Tarannum S, Hasan MM, et al. Factors influencing the prevalence of stunting among children aged below five years in Bangladesh. Food and Nutrition Bulletin. 2017; 38(3): 291-301.

20. Roche ML, Creed-Kanashiro HM, Tuesta I, Kuhnlein HV. Traditional food diversity predicts dietary quality for the Awajún in the Peruvian Amazon. Public Health Nutr. 2008;11(5):457-465.

21. Lipoeto NI, Geok Lin K, Angeles-Agdeppa I. Food consumption patterns and nutrition transition in South-East Asia. Public Health Nutrition. 2013;16(9):1637-1643.

22. Olack B, Burke H, Cosmas L, Bamrah S, Dooling K, Feikin DR, et al. Nutritional status of under-five children living in an informal urban settlement in Nairobi, Kenya. Journal of Health, Population and Nutrition. 2011; 29(4): 357-63.

23. Derso T, Tariku A, Biks GA, Wassie MM. Stunting, wasting and associated factors among children aged 6-24 months in Dabat health and demographic surveillance system site: a community based cross-sectional study in Ethiopia. BMC Pediatr. 2017; 17(1): 1-9. 